\title{
COOPERATIVAS DE SERVIÇOS MÉDICOS COMO SÓCIAS DE OUTROS TIPOS SOCIETÁRIOS
}

\section{Fábio Martins Bonilha Curi}

Aluno do quarto ano do curso de direito da Universidade Estadual Paulista - UNESP - Faculdade de História, Direito e Serviço Social de Franca.

e-mail: fabiombcuri@hotmail.com.

RESUMO: $O$ artigo analisa de forma geral, sem pretender esgotar o assunto, a situação de diversas cooperativas de serviços médicos que se tornam sócias de hospitais e farmácias sob a forma de sociedade empresária. Nesse sentido, tratarse-á da previsão legal que dispõe sobre essa possibilidade, dos reflexos que essa situação traz para consumidores e para os próprios cooperados e, principalmente, se tal fato se enquadra nos princípios cooperativistas. Para tanto, em fase inicial, realiza-se um estudo da expansão cooperativista, apresentando as diversas características que esta instituição adquiriu durante a história. Posteriormente, estuda-se a importância dos princípios no sistema jurídico e a dimensão de sua atuação. Analisa-se, também, o atual sistema de saúde, com seus problemas atuais, dando especial atenção à importância das cooperativas de serviços médicos neste contexto. Após essa análise, adentra-se focalizando os problemas dos hospitais e das farmácias constituídos em forma de sociedades empresárias. Apresentam-se como sugestões que os próprios médicos cooperados proíbam tal prática por meio de previsão estatutária; e que constituam essas instituições também sob a forma de cooperativas de serviços, o que trará segurança aos cooperados e maior acesso aos consumidores, possibilitando a ampliação das atividades cooperativas.

PALAVRAS-CHAVE: Cooperativas médicas; Sociedades limitadas; Sistema nacional de saúde; Princípios cooperativos; Cooperativas de serviços; Previsão estatutária. 


\section{INTRODUÇÃO}

Com a finalidade de atender ao preceito expresso na Constituição Federal em seu art. 174, §2.-., o Estado tenta incentivar as cooperativas, propondo-Ihes melhores condições tributárias e trabalhistas. Dessa forma, se calculados impostos como INSS, FGTS, Sesi/ Sesc, Senai/ Senac, entre outros menos específicos, podese afirmar que a contratação de um funcionário é, em média, 20\% mais cara do que a inclusão de um cooperado.

Incontestável é a necessidades de tais incentivos, visto que as cooperativas podem ser uma ótima alternativa ao desemprego, à subordinação e, além disso, através de seus serviços podem oferecer mais possibilidades aos consumidores. No entanto, como afirma Celso Ribeiro Bastos':

nas cooperativas constata-se que os objetivos efetivamente alcançados ficam muito aquém daqueles para os quais foram criadas.

Assim, é que se mostra muito freqüente o desvirtuamento do espírito cooperativo em favor do espírito de lucratividade, desviando a entidade por meios nos mais das vezes espúrios, dos fins sociais

E, assim é, atualmente, a situação de algumas cooperativas de serviços médicos que atuam no Brasil, pois, apesar de estarem estritamente no âmbito da legalidade, não atuam sob a égide dos princípios que regem o cooperativismo.

Nestes termos, constituem hospitais e farmácias, na forma de sociedades limitadas, e acabam desviando-se da finalidade cooperativa de não objetivação de lucro, sem que haja, por tal fato, uma responsabilização de seu quadro administrativo.

\section{HISTÓRICO DAS COOPERATIVAS}

Para mensurar a situação hodierna das cooperativas médicas, faz-se necessário um estudo histórico das cooperativas, analisando a finalidade para qual foram constituídas.

1 BASTOS, Ribeiro Celso e MARTINS, Ives Gandra: Comentários à Constituição do Brasil. v. 7 São Paulo: Saraiva, 1990. p.119. 
Dessa forma, as sociedades cooperativas surgiram como uma forma de superação capitalista, com conteúdos ideológicos amplamente democráticos, sendo consideradas por alguns, como Robert $\mathrm{Owen}^{2}$, um verdadeiro caminho para uma nova ordem econômica e social.

Os próprios liberais e fisiocratas capitalistas entendiam que as cooperativas podiam ser uma forma que atenuaria as características egoísticas e concentradas do

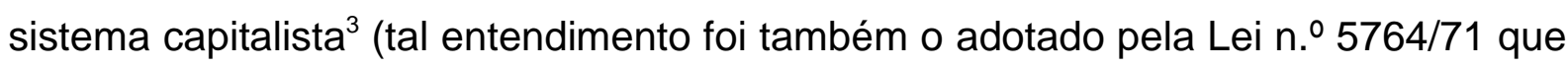
rege o cooperativismo nacional).

Nosso atual sistema jurídico não foi diferente. Através da Constituição Federal de 1988, procurou incentivar o cooperativismo, abrangendo-o em seu artigo

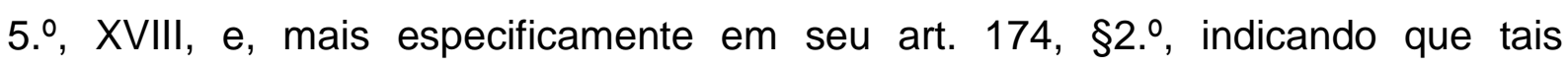
entidades não precisam receber autorização pública para funcionar e que a função do Estado será o incentivo e a fiscalização das cooperativas já existentes.

Esses incentivos devem-se às características de organização interna que regem as cooperativas, uma vez que nelas se encontram diversos princípios democráticos, como por exemplo, o fato de que a quantidade de quotas não ser proporcional ao número de votos, já que cada cooperado tem direito a um voto independente do número de quotas que possui, ou mesmo o princípio das portas abertas, que transmite a idéia de que a cooperativa é uma instituição aberta a todas as pessoas aptas a utilizar seus serviços, não discriminando raça, religião ou posição social ${ }^{4}$.

\section{LEGALIDADE E PRINCÍPIOS COOPERATIVISTAS}

Estes princípios cooperativistas, assim como qualquer princípio, devem ser guias para as legislações e para a classificação jurídica das atividades realizadas por essas entidades, não podendo entre eles, haver contradição.

Roque Carraza, muito bem define esta questão, quando determina a noção de princípios. Este autor parte da concepção de Platão para quem o princípio é o 2000. p.14

2 RECH, Daniel. Cooperativas: Uma Alternativa de Organização Popular. Rio de Janeiro: DP\&A,

3 Idem

4 KRÜGER, Cátia Denise Gress: Cooperativismo e o Novo Código Civil. Organização: Guilherme Krueguer. Belo Horizonte: Mandamentos, 2003 p.84. 
fundamento de raciocínio, passa por Kant, que expressou como princípio toda a proposição geral que pode servir como premissa maior num silogismo, para concluir que:

Princípio jurídico é um enunciado lógico, implícito ou explícito, que, por sua generalidade, ocupa posição de preeminência nos vastos quadrantes do Direito e, por isso mesmo, vincula de modo inexorável, o entendimento e a aplicação das normas jurídicas que com ele se conectam ${ }^{5}$

Com essas características é que surgem os princípios cooperativistas, pois são eles que nortearam as legislações que regem o cooperativismo e, sob a égide deles é que deve-se desenvolver a atividade das cooperativas.

\section{FUNÇÃO ATUAL DAS COOPERATIVAS MÉDICAS}

A legislação brasileira, primeiro através da Lei 5764/1971 e, posteriormente através da Constituição Federal de 1988, consagrou tais princípios cooperativistas, confirmando a sua importância e fornecendo a possibilidade de expansão das cooperativas, fato que ocorreu nas últimas décadas, no cenário nacional.

Dentre as cooperativas que se desenvolveram no Brasil, as de serviços médicos ganharam destaque, visto que conseguiram angariar clientes em diversas regiões do país, tornando-se uma ótima opção para a sociedade e, principalmente, para médicos, que tal como em outras profissões, lutam com a concorrência.

Assim, estas entidades poderiam ajudar sensivelmente na melhora do sistema de saúde nacional, pois apesar de serem uma entidade privada, não necessitam da existência de lucro constante para a sua sobrevivência, pois, como ensina Amador Paes de Almeida ${ }^{6}$,

o lucro está para a sociedade cooperativa na mesma situação em que está para empresa pública, constituindo-se em mera decorrência de uma gestão profícua, mesmo porque, dificilmente manter-se-á uma sociedade cooperativa deficitária

Porém, a atual situação não reflete bem isso. As cooperativas médicas atingem apenas uma pequena parcela da população, devido ao custo cada vez mais

\footnotetext{
${ }^{5}$ Curso de Direito Constitucional Tributário, 5. ${ }^{a}$ ed., São Paulo, Malheiros Editores,1997 p. 31.

${ }^{6}$ ALMEIDA, Amador Paes de. Manual das Sociedades Comerciais. 13. ed. São Paulo: Saraiva, 2003, p. 370.
} 
alto de seus serviços. Uma vez que, ao invés de apenas angariar clientes para os médicos, função deste tipo de cooperativa de trabalho, as cooperativas vendem planos, nos quais se agrega ao custo além da disponibilização dos médicos, serviços extras, como por exemplo, a existências de hospitais e farmácias, que ficam a disposição do usuário de tais cooperativas.

Estes hospitais e farmácias, não apenas encarecem o acesso a este tipo de cooperativa, mas outro problema a eles relativos é que são constituídos sob a forma de sociedades limitadas, tendo as próprias cooperativas como suas sócias, fato que desconfigura o princípios de não lucratividade dentro das cooperativas.

Isto porque, insofismável é o argumento de que as sociedades limitadas tem por objetivo a busca de lucros, logo, as cooperativas que se tornam sócias de sociedades empresárias, estão obtendo, ou pelo menos estão em busca, de lucros.

Este fato, não teria grande relevância, se ocorresse em situações de extrema exceção, mesmo porque há a essa possibilidade prevista no art. 88 da Lei 5764/71 que, possibilita a criação de sociedades empresariais com a finalidade de atenderem aos objetivos acessórios e complementares da atividade principal.

Porém, hodiernamente, todas as cidades de médio e grande porte possuem pelo menos um hospital e uma farmácia, com essas características, o que na maioria dos casos não se faz necessário, visto que há outros hospitais que poderiam ser conveniados às cooperativas. O que ocorre então, é um total descontrole de quais sociedades têm cooperativas como sócios e, para quais fins foram constituídas.

Este descontrole não havia à época em que a legislação foi constituída, pois neste período, a criação de outros tipos societários tendo cooperativas como sócias, era condicionada a existência de concessão de órgãos competentes.

No entanto, a redação foi modificada através de medida provisória (MP N.으․ 21.68-40 de 24 de agosto de 2001), que retirou do texto a necessidade de autorização, por incompatibilidade com o preceito do art. 5. inciso XVII da Constituição Federal de 1988, que tornou plena a liberdade de associação.

Esta garantia constitucional, extremamente importante para a existência de um Estado Democrático de Direito, acabou facilitando a constituição indiscriminada de tais entidades e vem gerando diversos problemas para a maioria dos médicos e consumidores destas cooperativas. 
Para a maioria dos médicos, estas instituições não são benéficas, pois geralmente estes hospitais e farmácias trazem prejuízos à cooperativa.

E porque tais órgãos trazem prejuízos?

A resposta, parece clara quando analisa-se a dificuldade de corrupção que a cooperativa em si possui, pois, justamente pelo fato de não visar lucro, o resultado financeiro é individual e é proporcional ao trabalho de cada médico, o que não ocorre nas sociedades empresariais, nestas, independente de quem está trabalhando, os lucros finais serão destinados aos sócios, que muitas vezes só contribuíram com capital.

Portanto, em sociedades empresariais, principalmente as limitadas que, costumeiramente, não possuem órgãos de fiscalização, problemas de desvios de verbas ocorrem com muito mais facilidade.

Já o prejuízo a consumidores e aos próprios cidadãos também se evidencia como dito acima, pois estes hospitais e farmácias, são tidos como supostos benefícios aos usuários fato que apenas encarecem ainda mais o acesso a estas cooperativas.

Além disso, se há realmente a necessidade de hospitais e de farmácias para o bom andamento da atividade principal das cooperativas, estes poderiam ser constituídos também sob a forma de cooperativas de consumo, nas quais distribui-se as melhores condições de preço a associados e a não associados, e os eventuais resultados líquidos verificados pelo balanço, pode-se converter em economia a favor dos consumidores ${ }^{7}$. Dessa forma, as atividades acessórias e complementares seriam supridas, sem que para isso haja a necessidade de busca por lucros.

Percebe-se então, que o fato de as cooperativas agirem em consonância com a lei quanto à criação indiscriminada de sociedades empresárias, não torna essa atividade inabalável, visto que, agindo desta forma, não estão respeitando o maior princípio cooperativista que é a não finalidade de lucro nas atividades da cooperativa.

Cabe ao nosso judiciário então, analisar mais retidamente os princípios cooperativistas, formando proposições sólidas para definir sobre a possibilidade de restringir a criação de sociedades empresariais tendo cooperativas como sócias.

\footnotetext{
${ }^{7}$ ALMEIDA, Amador Paes de. Manual das Sociedades Comerciais. 13. ed. São Paulo: Saraiva, 2003.
} 


\section{DEFINIÇÃO DE ATO COOPERATIVO EM ESTATUTO}

Uma outra possibilidade de restrição às cooperativas quanto ao fato de tornarem sócias de outros tipos societários, seria a expressa proibição no estatuto social destas instituições.

Isto pois, como na maioria dos casos as cooperativas são prejudiciais aos próprios médicos, estes, reunidos em assembléias poderiam optar pela proibição de construção de hospitais e farmácias que tenham as cooperativas como sócias.

Tal fato, surtiria efeitos em diversos sentidos, primeiro porque dificultaria ainda mais possíveis desvios de verbas, trazendo assim mais segurança para os cooperados; segundo, porque tal atitude diminuiria os custos que a cooperativa possui e facilitaria o acesso aos consumidores; finalmente, a previsão estatutária faria com que as atividades cooperativas adquirissem uma ampla publicidade, já que estaria registrada na Junta Comercial do Estado em que constituírem, o que facilitaria a fiscalização por parte dos consumidores e dos próprios médicos cooperados.

Neste contexto, apesar de não ser o tema do presente artigo, um importante adendo é a opção de prever todas as atividades que a cooperativa pratica em prol dos associados, o chamado ato cooperativo, em estatuto. Tal atitude é uma forma simples e que possibilita resolver diversos problemas que as cooperativas enfrentam. Já que o termo ato cooperativo é extremamente abstrato e, por não ser definido, traz diversos problemas de incidência tributária para as cooperativas.

Neste sentido uma opção seria a individualização das atividades que a cooperativa produz para seus associados e a expressa previsão dos mesmos em estatuto.

\section{CONCLUSÃO}

As cooperativas de serviços médicos possuem grande importância no atual sistema de saúde nacional. Assim, o fato de estarem atuando em conformidade com os princípios cooperativistas somente aumentaria esse valor.

Dessa forma, a constituição exacerbada de sociedades empresariais tendo cooperativas como sócias encarece o acesso aos usuários deste tipo de 
cooperativa, facilita a corrupção e demonstra um possível interesse por lucro buscado pelas cooperativas.

Por tudo isso, a constituição de hospitais e farmácias sob a forma de sociedades limitadas, deve ser controlada ou pelo judiciário, ou pelos próprios cooperados através da proibição expressa em estatuto social.

Além disso, se considerar a existência destes órgãos realmente indispensável para o bom andamento da atividade cooperativa, há a opção de os constituírem sob a forma de cooperativas de consumo, o que supriria a necessidade da cooperativa sem que houvesse a necessária busca por lucros que caracterizam a finalidade das sociedades empresárias.

\section{BIBLIOGRAFIA}

ALMEIDA, Amador Paes de. "Manual das Sociedades Comerciais". 13. ed. São Paulo, Saraiva, 2003.

AZEVEDO, Álvaro Vilaça, "Teoria Geral das Obrigações". 6. ed. São Paulo: Revista dos Tribunais, 1997.

BASTOS, Celso Ribeiro e MARTINS, Ives Gandra. Comentários à Constituição do Brasil. v.7. São Paulo: Saraiva, 1990.

BECHO, Renato Lopes. “Tributação das Cooperativas”. São Paulo: Dialética, 1998.

BORBA, José Edwaldo Tavares. "Direito Societário". Rio de Janeiro: Renovar, 2001.

BRITTO, Marcel. et. al. "O ato cooperativo e suas relações obrigacionais". Franca. UNESP. Faculdade de História, Direito e Serviço Social. (para a obtenção de grau de mestre em Direito).

BULGARELLI, Waldirio. "As sociedades cooperativas e a sua disciplina jurídica". São Paulo: Renovar, 1998.

CAHALI, Yussef Said. "Responsabilidade Civil Doutrina e Jurisprudência”. São Paulo: Saraiva, 1984.

CARRAZZA, Roque Antônio. "Curso de Direito Constitucional Tributário". 11. ed. São Paulo: Malheiros, 1998.

COMPARATO, Fábio Konder. "Ensaios e Pareceres de Direito Empresarial". Rio De Janeiro: Forense, 1978.

DINIZ, Maria Helena. "Direito Civil Brasileiro". v. 7. São Paulo: Saraiva, 2002.

FÁVARO, Vera Lúcia. "Responsabilidade dos Administradores de Sociedades Empresariais". Franca. UNESP. Faculdade de História, Direito e Serviço Social. (para a obtenção do grau de mestre em Direito). 
JUNIOR, Luiz Emygdio F. da Rosa. "Manual de Direito Financeiro \& Tributário". Rio de Janeiro, Renovar: 2002.

KRUEGER, Guilherme. Cooperativismo e o Novo Código Civil. Belo Horizonte: Mandamentos, 2003. LANCHA, Raquel de Souza Palma. "O trabalho na UNIMED de Franca: analise da qualidade total'. Franca. UNESP. Faculdade de História, Direito e Serviço Social. (para a obtenção do grau de mestre em Serviço Social).

LIMA, Reginaldo Ferreira. "Direito Cooperativo Tributário- comentários à Lei das Sociedades Cooperativas (Lei n. 5.764/71)”. São Paulo: Max Limonad, 1997.

MARTIN, Fran. "Curso de Direito Comercial". 22. ed. Rio de Janeiro: Forense, 1998.

MARTINS, Sergio Pinto. "Cooperativas de Trabalho". São Paulo: Atlas, 2003.

RECH, Daniel. "Cooperativas: uma alternativa de organização popular". Rio de Janeiro: DP\&A, 2000.

SILVA, José Afonso da. "Curso de Direito Constitucional Positivo". São Paulo, Revista dos Tribunais: 1990.

SIQUEIRA, Paulo César Andrade. "Direito Cooperativo Brasileiro (Comentários à Lei 5.764/71)". São Paulo: Dialética, 2004.

STRAPASSON, Thiago. "A Responsabilidade dos Administradores de Empresas em Matéria Tributária" . Franca. UNESP. Faculdade de História, Direito e Serviço Social. (para a obtenção do grau de bacharel em Direito).

TOLEDO, Paulo Fernando Campos Salles de. "Administração nas Sociedades por Quotas de Responsabilidade Limitadas". Revista dos Advogados, Associação dos Advogados São Paulo, n.57, jan, 2000.

VENOSA, Silvio de Salvo. "Direito Civil - Parte Geral". São Paulo: Atlas, 2003.

WALD, Arnoldo. "Estudos e Pareceres de Direito Comercial". São Paulo: Revista dos Tribunais, 1972.

WOLF, Cláudio Juvenal. "Regime da unimilitância nas 'cooperativas' Unimed'. Jus Navigandi, Teresina, a. 7, n. 113, 25 out. 2003. Disponível em: http://www.jus.com.br/doutrina/texto. Acesso em: 06 out. 2004. 